\title{
Cranioorbital fibrous dysplasia: with emphasis on visual impairment and current surgical management
}

\author{
Aaron S. Dumont, M.D., Paul T. Boulos, M.D., John A. Jane, Jr., M.D., \\ Dilantha B. Ellegala, M.D., Steven A. Newman, M.D., and John A. Jane, Sr., M.D., Ph.D. \\ Departments of Neurological Surgery and Ophthalmology, University of Virginia, Charlottesville, Virginia
}

\begin{abstract}
Fibrous dysplasia is a benign but slowly progressive disorder of bone in which normal cancellous bone is replaced by immature woven bone and fibrous tissue. Significant deformity and both acute and chronic visual impairment can result. A contemporary understanding of fibrous dysplasia, emphasizing the origins of visual impairment, indications for decompressive surgery, and the techniques for correction of the cosmetic deformity are presented.

In their experience and review of the literature, the authors found the most frequent clinical presentations to be exophthalmos, displacement of the globe, abnormalities of extraocular motility, cosmetic deformity, and visual impairment. Although traditionally the cause of visual impairment has been ascribed to impingement of the optic canal on the optic nerve, the authors' experience is that the most common cause of visual loss is cystic degeneration of the tumor, particularly with those involving the anterior clinoid process. Exophthalmos and optic canal stenosis are less common causes of visual impairment. Indications for surgical intervention include acute and/or serially radiographically documented and relentless visual impairment and significant cosmetic deformity. Individualized management strategies are also discussed.
\end{abstract}

KEY WORDS • fibrous dysplasia • visual impairment • orbit • orbital decompression

Fibrous dysplasia has been present since antiquity. It was noted, for example, in the report on a skull found in Tennessee dated 1480 A.D. and in another on the skeleton of a seventh century Anglo Saxon. ${ }^{18,51}$ Fibrous dysplasia was first reliably recognized in 1891 by von Recklinghausen $^{48}$ in a report in which he describes patients with a disorder of bone characterized by fibrotic changes and deformity. The author used the term "osteitis fibrosa generalisata" to denote this condition. It was not until several decades later that Lichtenstein and Jaffe ${ }^{31}$ proposed the term "fibrous dysplasia" as the preferred nomenclature for this characteristic disorder of bone. Lichtenstein and Jaffe observed that fibrous dysplasia could affect single as well as multiple bones; thus, a rudimentary report of its monostotic and polyostotic forms of the disorder was born. ${ }^{31}$

Shortly thereafter Dandy ${ }^{8}$ published his classic monograph on orbital tumors. In his first case he described a 28year-old woman who presented with exophthalmos and severe headaches. She had previously been treated by W. W. Keen and underwent surgery in which exploration and partial extirpation of the orbital roof was undertaken in the pursuit of tumor within the orbit. In this patient Dandy had diagnosed a "diffuse osteoma of the skull and orbit," al-

Abbreviations used in this paper: $\mathrm{ACP}=$ anterior clinoid process; $\mathrm{CT}=$ computerized tomography; $\mathrm{MR}=$ magnetic resonance. though the skull radiographs, drawings, and description of the bone as "soft and spongy" suggest, rather, that this case likely represented what is now termed fibrous dysplasia.

Contemporaneously, $\mathrm{McCune}^{33}$ and Albright, et al., ${ }^{1}$ recognized the frequent correlation between this condition and coexisting endocrinopathy. The triad of polyostotic fibrous dysplasia, areas of cutaneous pigmentation (caféau-lait spots), and precocious puberty was subsequently termed McCune-Albright syndrome. Since the time of these important pioneering contributions, considerable advancement has occurred in our understanding of the nature of fibrous dysplasia and its appropriate treatment.

Fibrous dysplasia is a benign but slowly progressive bone disorder of unknown origin in which normal cancellous bone is replaced by immature woven bone and fibrous tissue. It is a relatively uncommon, nonfamilial congential disorder of bone ${ }^{41}$ that is usually manifested before the third decade of life. ${ }^{15}$ There is no sex preference. ${ }^{41} \mathrm{Fi}$ brous dysplasia comprises approximately $2.5 \%$ of all bone tumors and nearly $7.5 \%$ of benign bone neoplasms. ${ }^{14,22} \mathrm{It}$ may be isolated in its monostotic form (representing $70 \%$ of cases and most commonly affecting the ribs and femur), or it may involve multiple foci including the long bones, skull, and cranial base. Of significance, in 50 to $100 \%$ of patients with the polyostotic form and in $10 \%$ 
with the monostotic variant craniofacial involvement is present. ${ }^{41}$ There is a predilection for involvement of the frontal, sphenoid, ethmoid, and maxillary bone complexes. ${ }^{35}$ Various terms have been applied to fibrous dysplasia with craniofacial involvement, including craniomaxillofacial, cranioorbital, frontoorbital, orbital, and complex fibrous dysplasia. ${ }^{14,23,37,38}$ Because the orbit is frequently involved, there are related problems including exophthalmos, displacement of the globe, abnormalities of extraocular motility, cosmetic deformity, and possible compromise of the optic nerve manifesting as visual impairment.

The primary purpose of the present study is to discuss fibrous dysplasia in light of our experience at the University of Virginia in the care of patients with this condition. Knowledge and experience gleaned from the treatment of these patients over the past three decades has allowed us to develop and refine appropriate treatment paradigms in tandem with our evolving understanding of this disease. The origins of visual impairment in fibrous dysplasia will be discussed, as well as its implications for surgical management. Indications for and methods of surgical treatment will be outlined. Because fibrous dysplasia with orbital involvement is rarely limited to the orbit itself, neurosurgical expertise in its comprehensive management is mandated. The surgical management of fibrous dysplasia is multifaceted; its many important surgicalrelated principles and axioms serve as an excellent model of orbital surgery. The contemporary literature will also be reviewed in the process.

\section{Pathological Features}

Fibrous dysplasia appears to arise from a perturbation in the mesenchymal precursor of bone, producing a defect in osteoblastic differentiation and subsequent maturation of bone (that is, a defect in cells of the osteogenic lineage). ${ }^{32,42}$ Although the origin is unknown, recent molecular biological findings have provided some insight. One of the putative defects appears to involve a missense mutation, which gives rise to an anomaly of intracellular signaling that produces increased cell proliferation and inappropriate cell differentiation, resulting in a disorganized fibrotic bone matrix..$^{32,42}$ Additionally, increased interleukin-6 may also play a role in the development of fibrous dysplasia. ${ }^{52}$

Fibrous dysplasia is most commonly a benign disorder. Although typically considered progressive, active growth tends to diminish with time. ${ }^{29}$ Malignancies, however, have been reported in conjunction with fibrous dysplasia and may include, most commonly, osteosarcoma, as well as fibrosarcoma, chondrosarcoma, and malignant fibrohistiocytoma. ${ }^{43}$

Histologically, fibrous dysplasia appears as a nonneoplastic tissue mass in which multiple small and irregular spicules of immature bone are abundant. This is referred to as "woven bone," which is reminiscent of embryonic membranous bone because of the disordered nature of the spicules, absence of mature lamellae, and paucity of calcium. ${ }^{12}$ The woven bone is superimposed on a background of moderately cellular fibrous connective tissue..$^{22,25,41}$ The histological pattern appears to stablilize over time, and no difference is evident between that observed in adults and children. ${ }^{20}$

\section{Clinical Presentation}

Symptoms arise due to the expansion and impingement of bone on adjacent structures. The most common symptom is swelling or deformity of the affected site..$^{36}$ Based on our experience, other common presenting signs and symptoms of cranioorbital fibrous dysplasia include exophthalmos, displacement of the globe, abnormalities of extraocular motility, and visual impairment.

The definitive diagnosis of fibrous dysplasia is based on multiple factors. Data accrued from clinical, radiological, and histological examinations provide the basis for accurate diagnosis.

\section{Radiological Characteristics}

Fibrous dysplasia exhibits distinctive radiological characteristics. There have been three imaging-categorized forms of fibrous dysplasia: sclerotic, cystic (lytic), and mixed varieties. ${ }^{16,34}$ The mixed-type fibrous dysplasia is most common, representing $40 \%$ of cases. The sclerotic form comprises $35 \%$ of cases and typically involves the cranial base. Cystic fibrous dysplasia is least common. ${ }^{41}$ On plain radiographs the sclerotic form can appear to mimic Paget disease, neurofibromatosis, or meningioma. ${ }^{12}$ Involvement of the facial bones, however, is common with fibrous dysplasia but relatively uncommon with the other conditions. Computerized tomography demonstrates the classic "ground-glass" appearance of the sclerotic form and provides excellent visualization of the extent to which the disease impinges on the cranial base foramina and other structures. ${ }^{12}$ Three-dimensional CT scanning also is extremely useful in delineating the lesion and guiding the surgeon when intervention is being contemplated. ${ }^{53}$ Cystic and mixed forms appear inhomogeneous in texture in the expanded bone on CT scans. ${ }^{12}$ Magnetic resonance imaging offers excellent definition of soft-tissue and ocular involvement and allows assessment of adjacent neurovascular structures. ${ }^{5,19}$ Of particular usefulness, MR imaging demonstrates cystic change (or mucoceles) as evident by very high signal from the cystic component seen on $\mathrm{T}_{2}$-weighted images and very low signal from bone sclerosis observed on $\mathrm{T}_{2}$-weighted images. ${ }^{12}$ Enhancement of pathological tissue is commonly observed on MR imaging but is more difficult to discern on CT scanning. Lytic areas are suggestive of malignant degeneration, particularly when viewed to expand on repeated imaging. ${ }^{12}$

\section{Visual Impairment in Fibrous Dysplasia}

Of all the sequelae of fibrous dysplasia, visual impairment is the most feared and potentially debilitating. Visual loss also represents the most common neurological complication of fibrous dysplasia affecting the skull. ${ }^{44}$ As such, visual impairment has received considerable attention; much has been published on its causes and putative treatment. Elucidation of underlying causes of visual impairment has important implications for the planning of therapeutic interventions: treatments must be targeted against appropriate pathological substrates and not on coincident and unrelated phenomena.

Visual impairment in patients with fibrous dysplasia may include, alone or in combination, perturbances in 


\section{Cranioorbital fibrous dysplasia}

color vision, central and peripheral field defects, and afferent papillary defects. It may occur in a chronic and progressive manner or may manifest in an acute and impressive fashion. ${ }^{4,27}$ Although fibrous dysplasia-induced visual impairment is certainly well documented, its pathoetiological basis and indications for treatment are controversial.

Visual impairment has been ascribed to a multitude of underlying pathological processes. One of these processes appears to involve progressive diminution of optic nerve venous drainage and, ultimately, retinal ischemia that develops due to optic nerve compression resulting from fibrous dysplasia-related optic canal stenosis. ${ }^{4,41}$ Because the arrangement of fibers within the optic nerve at the optic canal is such that the peripheral fibers run circumferentially along the periphery of the nerve, central vision may be preserved in cases in which there are peripheral visual field defects. ${ }^{41}$ Other explanations include exophthalmos-induced optic nerve traction, sinus mucocele formation, with increased intraorbital pressure, spontaneous hemorrhage, bone cyst formation, or rare vascular events. $4,7,9,10,14,22,28,30,35,39,40$ More recently, our group and others have questioned whether the most common cause of visual loss in fibrous dysplasia is indeed bone overgrowth-induced optic canal stenosis. This traditionally held belief may not be supported after careful scrutiny and critical analysis, particularly of cases in which quality CT or MR imaging studies and careful neuroophthalmological data are available.

Michael and colleagues ${ }^{35}$ have recently reviewed the current literature concerning visual loss in fibrous dysplasia. The impetus for this review stemmed from the authors' case report of a patient who experienced visual loss secondary to a mass of cystic-appearing fibrous dysplasia that compressed the medial surface of the optic nerve in a nonstenotic optic canal. They reviewed cases of fibrous dysplasia-related visual loss reported from the beginning of the CT/MR imaging era. ${ }^{26,35,46,47,50}$ Consequently, they examined 20 cases of patients with visual loss in which there were sufficient CT or MR imaging data to allow meaningful analyses. Of these 20 cases, visual loss was attributed to underlying disease other than optic canal stenosis in 16 patients. Six patients were found to be afflicted with cystic fibrous dysplasia, four with hemorrhagic lesions, four with mucoceles, and two with "aneurysmal bone cysts."

In our group's experience, the most common cause of visual impairment in orbit-related fibrous dysplasia is cystic degeneration within the tumor itself, most commonly involving the ACP (Fig. 1). Cystic degeneration of tumor has not been previously described as a common cause of visual loss in fibrous dysplasia. We have treated several patients in whom visual loss was observed in conjunction with cystic degeneration of the ACP but in whom no optic canal stenosis was apparent. Visual loss was less commonly noted in association with exophthalmos and/or inferior globe displacement (with subsequent optic nerve traction) and with true optic canal stenosis.

Knowledge of the underlying causes of visual loss in fibrous dysplasia is important for treatment. That visual loss in fibrous dysplasia is not usually due to optic canal stenosis affects our acceptance of current treatment para-

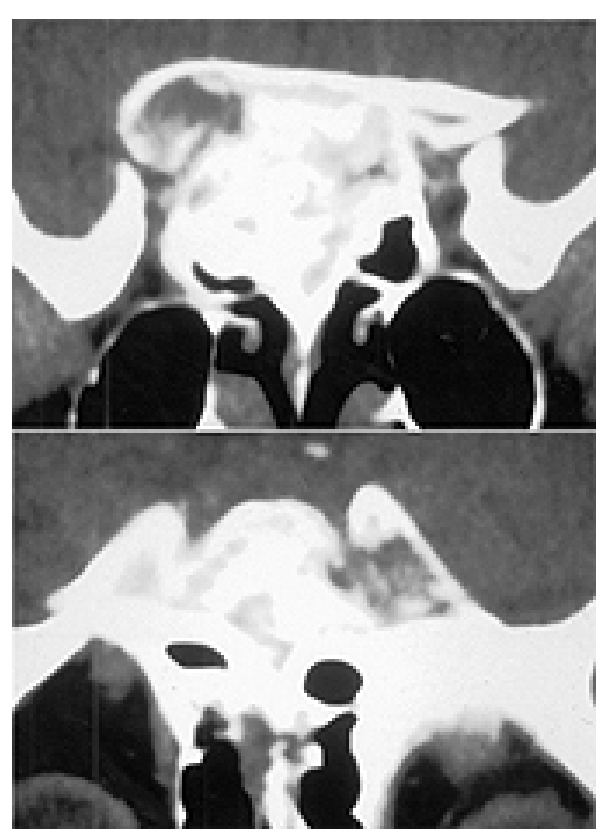

Fig. 1. Cystic degeneration of fibrous dysplasia with involvement of the ACP. Visual loss was associated with this lesion. Upper: Axial nonenhanced CT scan revealing cystic change within the ACP. Lower: Coronal nonenhanced CT scan demonstrating cystic degeneration of the ACP and immediate vicinity.

digms. Several authors have advocated routine optic canal decompression (as a prophylactic measure or after onset of visual symptoms), but this procedure is associated with visual loss as a complication in and of itself. In fact, iatrogenic causes probably represent the most common basis for visual loss in patients with fibrous dysplasia. Hence, an evolving knowledge of visual impairment and its causes in fibrous dysplasia provides a rational basis for individualized treatment of patients in whom orbital variations of this disorder are present.

\section{Management of Fibrous Dysplasia}

The establishment of appropriate therapy for this condition has been hindered by its relative rarity and by the paucity of quality reports in which adequate documentation, including careful imaging studies, is presented. Treatment options have included conservative management with clinical and radiological follow up, medical management, and surgical intervention. Radiotherapy in fibrous dysplasia is unproven as an effective treatment modality. The $44 \%$ incidence of malignant transformation in patients with fibrous dysplasia who undergo radiotherapy further contradicts its use. ${ }^{3}$

\section{Conservative Management}

Conservative management may be indicated if predicated on sound knowledge of a patient's clinical status and radiological findings. A patient with preserved vision and acceptable or minimal cosmetic deformity may be a candidate for serial clinical and radiological observation. Visual assessment should be meticulously performed at each visit. Radiological data, of course, should be interpreted in 


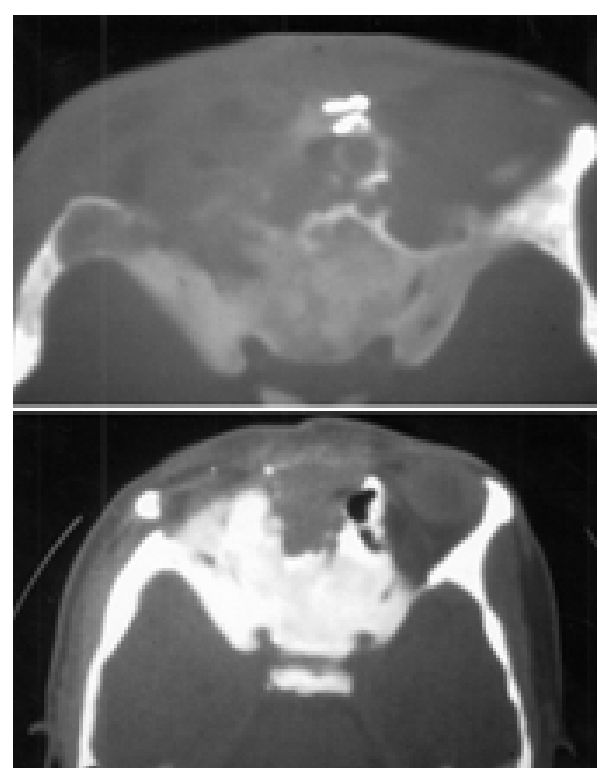

Fig. 2. Computerized tomography studies obtained in a patient with fibrous dysplasia diagnosed at age 6 years. Upper: First study obtained in 1986. The optic canals are not extensively compromised. Lower: Follow-up study obtained in 1995 revealing bilateral compromise of the optic canals. Because visual function was stable, surgical intervention was not warranted. Visual function remains preserved at most recent follow up.

light of clinical correlations. Optic canal stenosis is not an indication for surgical intervention if visual function is preserved. Consider, for example, the case of one patient (Fig. 2) in whom fibrous dysplasia was diagnosed at age 6 years. At an outside institution, a prophylactic right frontal craniotomy was performed to alleviate compromise of the right optic nerve. Postoperatively, the patient experienced complete visual loss in the right eye. As visual function was preserved in the left optic nerve, surgical intervention was not undertaken. The first CT scan was obtained in 1986. During the follow-up period, visual function was preserved in the left eye. On repeat CT examination in 1995, however, bilateral compromise of the optic canals was seen. Given the patient's stable visual function, surgical intervention again was not undertaken. The patient continues to be followed, and no changes in vision were demonstrated at the most recent follow-up visit.

Acute changes heralded by the sudden onset of diplopia, pain, or changes in visual function must be seriously considered and may represent coexisting disease such as cystic changes or the presence of hemorrhage or mucoceles. In these cases in which disease is clearly correlated with acute symptoms, expedient surgical intervention may be warranted.

\section{Medical Management}

Medical management of fibrous dysplasia remains poorly characterized. At present, no medical therapy has been clearly proven to cure or impede the progression of fibrous dysplasia. Medications, such as bisphosphonates, calcitonin, and mithramycin, targeted at reducing bone resorption/osteoclastic activity have been prescribed based on the premise that increased osteoclastic activity is seen with fibrous dysplasia. Preliminary data appear promising although inconclusive. ${ }^{6,49}$ Corticosteroid agents have also been used in the care of patients with fibrous dysplasia. Systemic corticosteroids have been used successfully as a temporizing measure in patients with acute visual loss. ${ }^{2}$ Long-term nonoperative reversal of visual loss is unlikely with corticosteroid use alone. Visual function can deteriorate suddenly and progress to complete and permanent dysfunction, and steroids should therefore not be used as the sole treatment in such instances. In preparation for surgical intervention, we have treated patients with corticosteroids when acute visual loss has occurred.

\section{Surgical Management}

Surgical intervention may be indicated when perceived and unacceptable cosmetic deformity is present or significant, acute, and/or progressive visual impairment is documented by serial examinations. The basic tenets of operative intervention include the improvement of cosmetic deformity and the preservation or improvement of neurological function.

Surgery for Cosmesis. Surgery for correction of cosmetic deformities is tailored to the individual patient. Depending on the type and degree of bone involvement and the patient's preferences, we have performed procedures ranging from cranioorbital shaping and remodeling to extensive resection.

In patients in whom bone involvement is limited, cranioorbital shaping may be conducted. In such procedures the pathological bone may not completely removed; however, the residual involved bone is usually slow to grow. Cranioorbital burring and remodeling can provide dramatic cosmetic improvements. In a 39-year-old woman with a long history of progressive deformity the senior author (J.A.J., Sr.) performed this procedure to improve cosmesis. ${ }^{24}$ Because the patient was most concerned with the prominence of her forehead, direct bone remodeling was undertaken via a bicornal incision. The reshaping of her frontal bone, orbital rims, and intraorbital regions provided significant and enduring cosmetic improvement, much to the patient's satisfaction. ${ }^{24}$

When bone involvement is more extensive in patients with fibrous dysplasia, simple burring and remodeling is inadequate; aggressive resection and subsequent reconstruction should be undertaken. Knowledge of the principles of cranial base surgery are often useful when complete resection and reconstruction are performed. In the authors' practice, in patients with extensive bone involvement, bone resection has been performed in conjunction with cranioplasty in which acrylic is used; cosmetic results have been excellent. Figure 3 shows a patient in whom cosmetic deformity developed over a span of 15 years. This patient was taken to the operating room and a bicoronal incision was made (Fig. 4). Complete resection of the frontal bone complex was performed, and the resulting defect was immediately reconstructed using plates and acrylic. The final cosmetic results are shown in Fig. 4.

Another frequent cosmetic manifestation of fibrous dysplasia is inferior displacement of the globe. Residual globe dystopia may occur following intervention if methylmethacrylate alone is used to reconstruct the forehead 


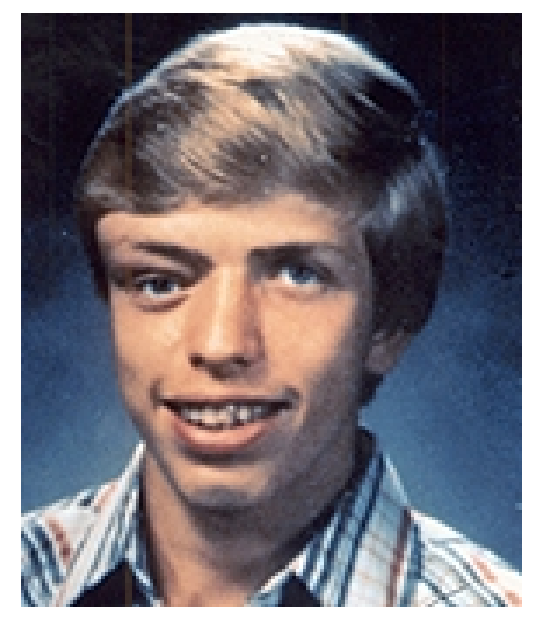

Fig. 3. Photograph of a patient with fibrous dysplasia and marked cosmetic deformity that progressed over a 15 -year period.

and orbital roof. This type of reconstruction often does not provide sufficient space for the globe to ascend. This is clearly illustrated by Dandy's case ${ }^{8}$ in which residual inferior displacement of the globe persisted following surgery. In cases such as these, the use of autologous or alloplastic material to reconstitute the orbital floor may adequately remove the downward compressive forces of the thickened orbital roof and restore the globe to its native location. Notwithstanding the above discussion, it is sometimes necessary to manually direct the globe superiorly to provide restoration of its location.

In the case illustrated in Fig. 5, inferior displacement of the globe and its treatment are demonstrated. The patient's ocular motility and visual acuity were intact, but her globe was displaced inferiorly. Imaging studies revealed the thickened inferior portion of the orbital roof displacing the globe inferiorly and anteriorly. She was taken to the operating room, and a bicoronal incision was used to provide access to the frontoorbital region. The entire supraorbital rim was removed using the Gigli saw, which readily cut through the thickened frontal bone, thereby providing direct access to the inferior aspect of the orbital roof. The orbital cavity was mechanically hollowed to the sphenoid, and the restrictive periorbita was opened to allow decompression. This effectively cured the patient's dystopia and exophthalmos. The original superior cortical table of the frontal bone was replaced rather than implanting alloplastic graft.

When globe dystopia and/or bone involvement is markedly prominent, a more extensive procedure is necessary. The entire involved bone may be resected and the defect reconstructed with methylmethacrylate, microplates, or other material.

Surgery for Visual Loss. Two main theories of surgical intervention have emerged that endeavor to preserve and/ or improve visual function in patients with fibrous dysplasia. The first attempts to prevent the occurrence of visual dysfunction through prophylactic intervention via intracranial decompression of the optic canal. The second aims to stabilize and/or restore visual function in patients with acute and/or progressive and relentless visual loss.

Two recent studies were conducted to examine prophy-

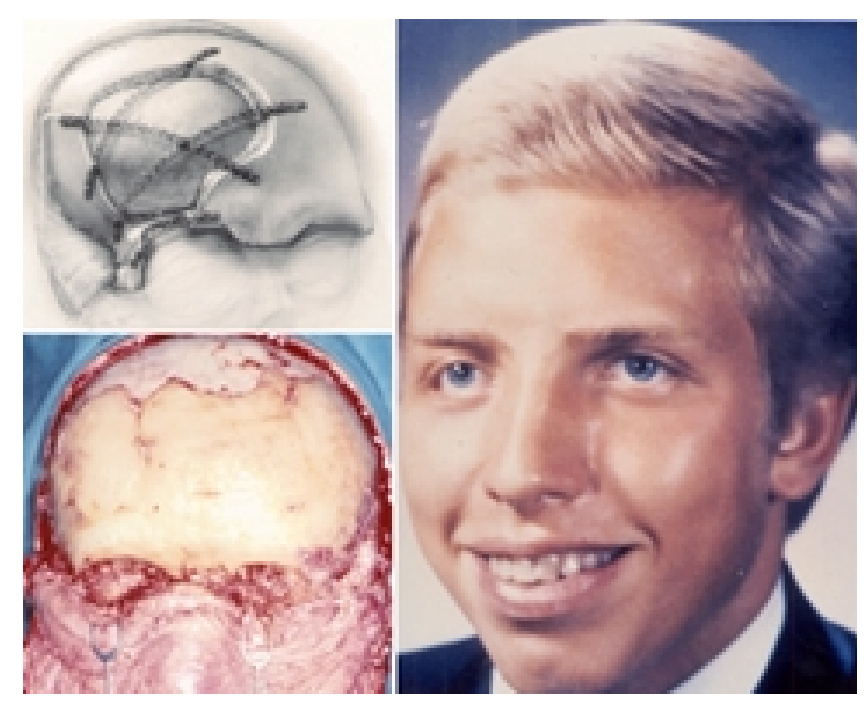

Fig. 4. Surgical procedure for the patient pictured in Fig. 3. Upper Left: Artist's illustration of resection of the involved frontal bone and orbit with microplate reconstruction to serve as a scaffolding for subsequent cranioplasty. Lower Left: Intraoperative photograph showing the completed cranioplasty as exposed through a bicoronal incision. Right: Photograph showing the final cosmetic result.

lactic optic canal decompression in patients with fibrous dysplasia. ${ }^{7,40}$ The emerging strategy of prophylactic optic canal decompression is predicated on the assumption that a stenotic optic canal is the most frequent cause of visual loss in patients with fibrous dysplasia. ${ }^{15,35,41}$ This assumption largely arose during the era predating the advent of $\mathrm{CT}$ and MR imaging. Advocates of this belief considered that the concomitant observations of fibrous dysplasia involving the optic canal and chronic visual loss proved that the former was the root cause of the latter. ${ }^{11,17,44}$ Clearly, optic canal stenosis can be entirely asymptomatic or a coincident occurrence in the face of another cause of visual loss. Moreover, the relationship between the frequency of optic canal stenosis and visual loss has never been proven. ${ }^{35}$ Furthermore, studies performed before CT and MR imaging were unable to identify other causes of visual loss such as cystic degeneration, mucoceles and hemorrhage, which, based on observations made in contemporary studies, are more frequent.

Chen, et al., ${ }^{7}$ demonstrated that prophylactic decompression of clinically or radiographically confirmed optic canal stenosis preserved vision in $67 \%$ of patients in whom visual symptoms were present. They found that visual loss persisting over a 1-month period was not improved by decompression of the optical canal. Papay and colleagues ${ }^{40}$ reported that optic canal decompression performed in five patients prior to signs of severe visual loss produced no disturbances in vision if performed before the onset of visual compromise. Others have expressed less enthusiasm about prophylactic optic canal decompression. ${ }^{21,45}$ In their review of cases of fibrous dysplasia with visual loss and CT- or MR-documentation, Michael and colleagues ${ }^{35}$ concluded that "prophylactic optic canal decompression may not have been of significant benefit in any of the 20 reported cases of fibrous dysplasia and visu- 
A. S. Dumont, et al.

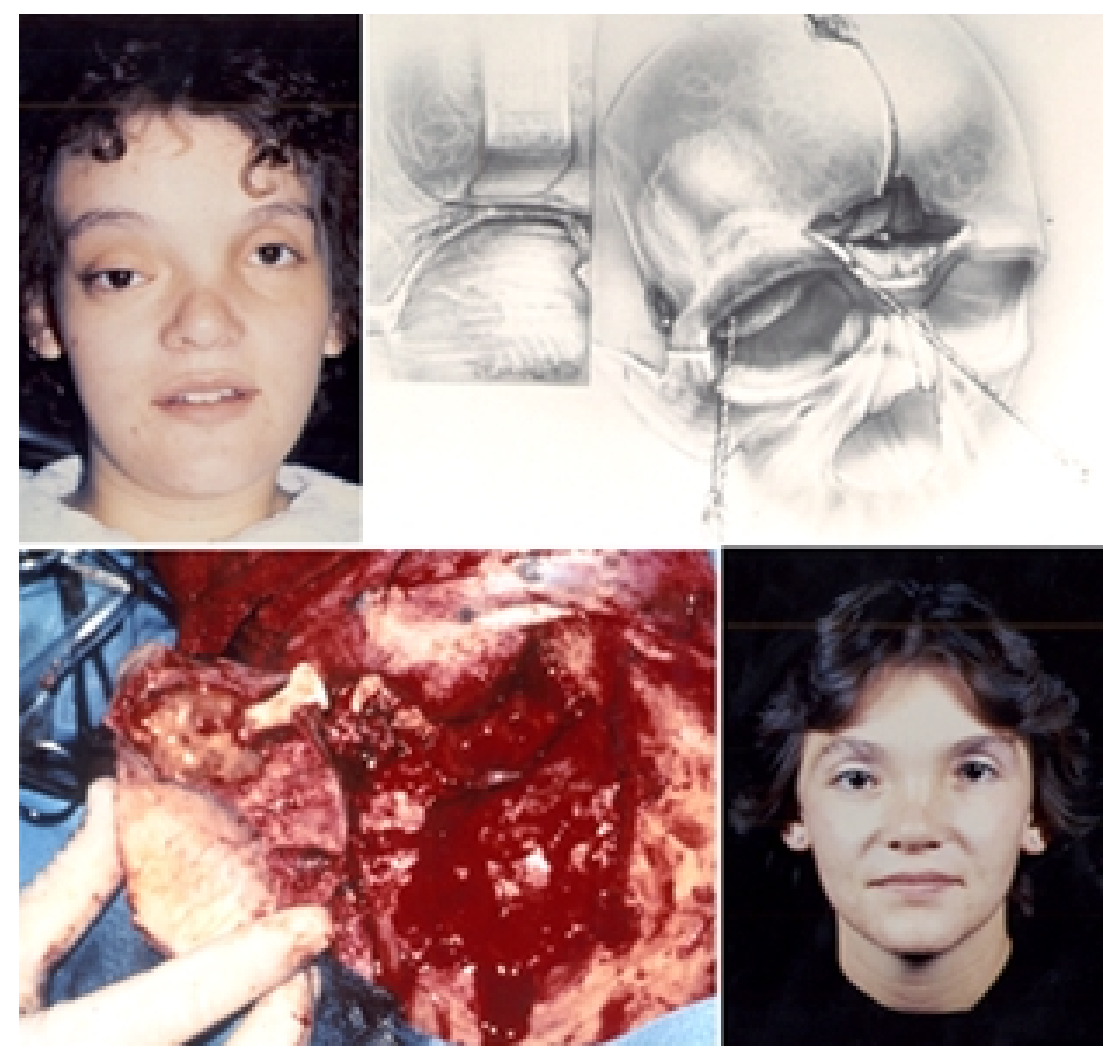

Fig. 5. Photographic and illustrative studies of a patient with normal visual acuity but inferior displacement of the globe and cosmetic deformity. Upper Left: Preoperative photograph demonstrating inferior displacement of the patient's right eye. Upper Right: Artist's depiction of a frontoorbital craniotomy in which the Gigli saw is used to provide direct access to the inferior aspect of the orbital roof. Lower Left: Intraoperative photograph demonstrating fibrous dysplasia with thickening of the bone plate following craniotomy. Lower Right: Photograph showing the final cosmetic result.

al loss." The risks of optic canal decompression are not trivial. Unilateral blindness after prophylactic transcranial optic canal decompression for fibrous dysplasia has been reported. ${ }^{13,36}$ We have never performed prophylactic optic canal decompression. We believe that a procedure for which there exists significant risk of debilitating neurological dysfunction in an asymptomatic patient, not to mention one that does not address the more common causes of visual loss in fibrous dysplasia, is not warranted. Optic canal decompression should only be undertaken in cases of acute and/or progressive and relentless serially radiologically documented visual loss, when optic canal stenosis is thought to be the apparent cause. Perhaps in the future prophylactic optic canal decompression may prove to be safe and efficacious in a highly selected subgroup of patients.

Surgery for acute and/or progressive chronic visual loss in patients with fibrous dysplasia is targeted at the underlying pathoanatomical substrate in each individual case. A frequent cause of visual loss, as previously mentioned, is enlargement of naturally occurring cysts within the fibrous dysplastic bone. These lesions do not constitute mucoceles as they are usually not lined with mucosa. Decompression of the cystic area and additional soft-bone involvement can restore visual acuity. When visual loss occurs in cases of extensive optic canal involvement and marked compromise of the optic nerve, decompression should be undertaken. Even when the surgical technique is meticulous, visual loss can occur postoperatively. ${ }^{24}$ The mechanism by which visual loss secondary to unroofing of the optic canal occurs remains poorly defined. ${ }^{24}$

\section{CONCLUSIONS}

Fibrous dysplasia is typically a benign but slowly progressive disorder of bone in which normal cancellous bone is overtaken by growth of immature woven bone and fibrous tissue. It has been present since antiquity, but only more recently has our understanding of this relatively uncommon but important disorder broadened. Patients afflicted with this disorder typically present with local deformity, exophthalmos, displacement of the globe, abnormalities of extraocular motility, and visual impairment.

Visual loss is the most feared complication of fibrous dysplasia involving the orbit. Although traditionally attributed to optic canal stenosis, other causes such as cystic degeneration within the pathological bone, hemorrhage, mucoceles, globe displacement-induced optic nerve traction appear more common. In the authors' practice, cystic degeneration is the most common cause of visual impairment, particularly with ACP involvement.

Surgical intervention is contemplated in cases of signif- 
icant cosmetic deformity, as well as in cases of acute and/ or chronic and relentless visual loss. Surgical management is tailored to the individual patient and is founded on intimate clinical, radiological, and pathoanatomical data. Prophylactic optic canal decompression, with its significant associated risks, is not indicated and specifically does not target the most common pathological substrates underlying visual loss. As perspectives on this unique condition evolve, our understanding of its natural history and our ability to select patients appropriately will improve. As we pay due attention to the specific disease and the patient's cosmetic concerns, and as our experiences increase, management paradigms will be refined and ultimately translated into improved patient outcomes.

\section{References}

1. Albright F, Butler MA, Hampton AO, et al: Syndrome characterized by osteitis fibrosa disseminata, areas of pigmentation and endocrine dysfunction with precocious puberty in females. N Engl J Med 216:727-746, 1937

2. Arroyo JG, Lessell S, Montgomery WW: Steroid-induced visual recovery in fibrous dysplasia. J Clin Neuroophthalmol 11: 259-261, 1991

3. Bibby K, McFadzean R: Fibrous dysplasia of the orbit. Br J Ophthalmol 78:266-270, 1994

4. Bland LI, Marchese MJ, McDonald JV: Acute monocular blindness secondary to fibrous dysplasia of the skull: a case report. Ann Ophthalmol 24:263-266, 1992

5. Casselman JW, De Jonge I, Neyt L, et al: MRI in craniofacial fibrous dysplasia. Neuroradiology 35:234-237, 1993

6. Chapurlat RD, Delmas PD, Liens D, et al: Long-term effects of intravenous pamidronate in fibrous dysplasia of bone. J Bone Miner Res 12:1746-1752, 1997

7. Chen YR, Breidahl A, Chang CN: Optic nerve decompression in fibrous dysplasia: indications, efficacy, and safety. Plast Reconstr Surg 99:22-33, 1997

8. Dandy WE: Orbital Tumors: Results Following the Transcranial Operative Attack. New York: Piest, 1941, pp 3-7

9. Derome PJ, Visot A, Akerman M: Ocular symptoms in fibrous dysplasia of the skull, in Smith JL (ed): Neuro-opthalmology Now! New York: Field, Rich, and Associates, 1986, pp 125-149

10. Donald PJ: Fibro-osseous diseases, in Donald PI, Gluckman JL, Rice DH (eds): The Sinuses. New York: Raven Press, 1995, pp 585

11. Donoso LA, Magargal LE, Eiferman RA: Fibrous dysplasia of the orbit with optic nerve decompression. Ann Ophthalmol 14:80-83, 1982

12. Doran SE, Gebarski SS, Hoff JT: Tumors of the skull, in Youmans JR (ed): Neurological Surgery, ed 4. Philadelphia: WB Saunders, 1996, Vol 4, pp 2998-3023

13. Edelstein C, Goldberg RA, Rubino G: Unilateral blindness after ipsilateral prophylactic transcranial optic canal decompression for fibrous dysplasia. Am J Ophthalmol 126:469-471, 1998

14. Edgerton MT, Persing JA, Jane JA: The surgical treatment of fibrous dysplasia. With emphasis on recent contributions from cranio-maxillo-facial surgery. Ann Surg 202:459-479, 1985

15. Finney HL, Roberts TS: Fibrous dysplasia of the skull with progressive cranial nerve involvement. Surg Neurol 6:341-343, 1976

16. Fries JW: The roentgen features of fibrous dysplasia of the skull and facial bones: a critical analysis of 39 pathologically proved cases. AJR 77:71, 1957

17. Gass JDM: Orbital and ocular involvement in fibrous dysplasia. South Med J 58:324-329, 1965

18. Gregg JB, Reed A: Monostotic fibrous dysplasia in the tempo- ral bone: a late prehistoric occurrence. Am J Phys Anthropol 52:587-593, 1980

19. Grimm MA, Hazelton T, Beck RW, et al: Postgadolinium enhancement of a compressive neuropathy of the optic nerve. AJNR 16:779-781, 1995

20. Harris WM, Dudley MR, Barry RJ: The natural history of fibrous dysplasia. J Bone Joint Surg Am 44:207-233, 1962

21. Henderson JW: Orbital Tumors, ed 3. New York: Raven Press, 1994, pp 155-161

22. Hoffman S, Jacoway JR, Krolls SO: Intraosseous and Parosteal Tumors of the Jaws, ed 2. Bethesda, MD: AFIP, 1987, pp 211-216

23. Jackson IT, Hide TA, Gomuwka PK, et al: Treatment of cranioorbital fibrous dysplasia. J Maxillofac Surg 10:138-141, 1982

24. Jane JA Sr, Newman SA: Transcranial orbital surgery. Clin Neurosurg 43:53-71, 1996

25. Joseph E, Kachhara R, Bhattacharya RN, et al: Fibrous dysplasia of the orbit in an infant. Pediatr Neurosurg 32:205-208, 2000

26. Joseph MP: Commentary on Papay FA, Morales L Jr, Flaharty $\mathrm{P}$, et al: Optic nerve decompression in cranial base fibrous dysplasia. J Craniofac Surg 6:11-13, 1995

27. Katz BJ, Nerad JA: Ophthalmic manifestations of fibrous dysplasia: a disease of children and adults. Ophthalmology 105: 2207-2215, 1998

28. Kurokawa Y, Sohma T, Tsuchita H, et al: Hemorrhage into fibrous dysplasia following minor head injury-effective decompression of the ophthalmic artery and optic nerve. Surg Neurol 32:421-426, 1989

29. Leeds N, Seaman W: Fibrous dysplasia of the skull and its differential diagnosis. Radiology 78:570-582, 1962

30. Liakos GM, Walker CB, Carruth JA: Ocular complications in craniofacial fibrous dysplasia. Br J Ophthalmol 63:611-616, 1979

31. Lichtenstein L, Jaffe HL: Fibrous dysplasia of bone: a condition affecting one, several or many bones, the graver cases of which may present abnormal pigmentation of skin, premature sexual development, hyperthyroidism or still other extraskeletal abnormalities. Arch Pathol 33:777, 1942

32. Marie PJ, de Pollak C, Chanson P, et al: Increased proliferation of osteoblastic cells expressing the activating Gs alpha mutation in monostotic and polyostotic fibrous dysplasia. Am J Pathol 150:1059-1069, 1997

33. McCune DJ: Osteitis fibrosa cystica: the case of a nine year old girl who also exhibits precocious puberty, multiple pigmentation of the skin and hyperthyroidism. Am J Dis Child 52:743, 1936

34. Mendelson DB, Hertanu Y, Cohen M, et al: Computed tomography of craniofacial fibrous dysplasia. J Comput Assist Tomogr 8:1062, 1984

35. Michael CB, Lee AG, Patrinely JR, et al: Visual loss associated with fibrous dysplasia of the anterior skull base. Case report and review of the literature. J Neurosurg 92:350-354, 2000

36. Moore AT, Buncic JR, Munro IR: Fibrous dysplasia of the orbit in childhood. Clinical features and management. Ophthalmology 92:12-20, 1985

37. Munro IR, Chen YR: Radical treatment for fronto-orbital fibrous dysplasia: the chain-link fence. Plast Reconstr Surg 67: 719-730, 1981

38. Munro IR, Lauritzen CG: Periorbital tumors, in Caronni E (ed): Craniofacial Surgery. Boston, MA: Little, Brown and Company, 1985, pp 329-344

39. Osguthorpe JD, Gudeman SK: Orbital complications of fibrous dysplasia. Otolaryngol Head Neck Surg 97:403-405, 1987

40. Papay FA, Morales L Jr, Flaharty P, et al: Optic nerve decompression in cranial base fibrous dysplasia. J Craniofac Surg 6: 5-14, 1995

41. Ricalde P, Horswell BB: Craniofacial fibrous dysplasia of the 
fronto-orbital region: a case series and literature review. J Oral Maxillofac Surg 59:157-168, 2001

42. Riminucci M, Fisher LW, Shenker A, et al: Fibrous dysplasia of bone in the McCune-Albright syndrome: abnormalities in bone formation. Am J Pathol 151:1587-1600, 1997

43. Ruggieri P, Sim FH, Bond JR, et al: Malignancies in fibrous dysplasia. Cancer 73:1411-1424, 1994

44. Sassin JF, Rosenberg RN: Neurological complications of fibrous dysplasia of the skull. Arch Neurol 18:363-369, 1968

45. Seiff SR: Optic nerve decompression in fibrous dysplasia: indications, efficacy, and safety. Plast Reconst Surg 100: 1611-1612, 1997

46. Sevel D, James HE, Burns R, et al: McCune-Albright syndrome (fibrous dysplasia) associated with an orbital tumor. Ann Ophthalmol 16:283-297, 1984

47. Steel DHW, Potts MJ: Bilateral sudden visual loss in Albright's syndrome. Br J Opthalmol 79:1149, 1995 (Letter)

48. von Recklinghausen FD: Die Fibrose oder deformierende Ostitis, die Osteomalacie und die osteoplastische carcinose in ihren gegenseitigen Beziehungen. Festschrift Rudolf Virchow zum 13. Oktober, Berlin, 1891

49. Weinstein RS: Long-term aminobisphosphonate treatment of fi- brous dysplasia: spectacular increase in bone density. J Bone Miner Res 12:1314-1315, 1997

50. Weisman JS, Hepler RS, Vinters HV: Reversible visual loss caused by fibrous dysplasia. Am J Ophthalmol 110:244-249, 1990

51. Wells C: Polyostotic fibrous dysplasia in a 7th century AngloSaxon. Br J Radiol 36:925-926, 1963

52. Yamamoto T, Ozono K, Kasayama S, et al: Increased IL-6 production by cells isolated from the fibrous dysplasia tissues in patients with McCune-Albright syndrome. J Clin Invest 98: 30-35, 1996

53. Zinreich SJ, Mattox DE, Kennedy DW, et al: 3-D CT for cranial facial and laryngeal surgery. Laryngoscope 98: 1212-1219, 1988

Manuscript received April 11, 2001.

Accepted in final form April 30, 2001.

Address reprint requests to: Aaron S. Dumont, M.D., Department of Neurological Surgery, Box 800212, University of Virginia Health Sciences Center, Charlottesville, Virginia 22908. email: asd2@virginia.edu. 